\title{
ANTIMICROBIAL AND ANTICANCER ACTIVITY OF SILVER NANOPARTICLES FROM EDIBLE MUSHROOM: A REVIEW
}

\author{
PRIYADARSHNI KC*, MAHALINGAM PU
}

Department of Biology, The Gandhigram Rural Institute- Deemed University, Gandhigram, Dindigul, Tamil Nadu, India. Email: priyakcdarshu@gmail.com

Received: 04 November 2016, Revised and Accepted: 08 December 2016

\begin{abstract}
Biologically inspired nanoparticle synthesis is currently a rapid expanding area of research in nanotechnology. Nanoparticle synthesis utilizing the bioresources such as plants and microbes appears to be a viable, low-cost, and eco-friendly approach. Especially mushrooms can be used for largescale synthesis of silver nanoparticles as mushroom produces many proteins that reduce the silver nitrate during the biosynthesis. Silver nanoparticles can be characterized using ultraviolet-visible (UV-VIS) spectroscopy, fourier transform infrared spectroscopy, X-ray diffraction, scanning electron microscopy, energy dispersive X-ray, and transmission electron microscope. Silver nanoparticles possess high antibacterial activity since silver in different forms has been extensively used as a medicine for curing diseases and promote wound healing. Silver nanoparticles have high surface specific area, which will lead to excellent antimicrobial activity as compared with bulk metallic silver. Further, the silver nanoparticles show anticancer activity against various cell lines such as human epidermoid larynx carcinoma (HEP-2), colon adenocarcinoma (HCT-116), breast adenocarcinoma (MCF-7), liver carcinoma (Hep-G2), and intestinal adenocarcinoma (Caco2) were well documented. This review intends to present green synthesis of silver nanoparticles and their application as antimicrobial and anticancer agents.
\end{abstract}

Keywords: Silver nanoparticles, Bioresources, Mushroom, Antimicrobial activity, Anticancer property.

(C) 2017 The Authors. Published by Innovare Academic Sciences Pvt Ltd. This is an open access article under the CC BY license (http://creativecommons. org/licenses/by/4. 0/) DOI: http://dx.doi.org/10.22159/ajpcr.2017.v10i3.16027

\section{INTRODUCTION}

Nanoparticles are the basic essential elements of nanotechnology and it exhibits fabulous advanced characteristic features based on their properties such as size, morphology, and other size-dependent properties [1]. These unique features of nanoparticles may lead to play a crucial role in a variety of surprising and interesting uses in biomedicine, energy science, optics, and other health-care applications [2,3]. Among the nanoparticles, nanosilver has potential applications in the field of biomedicine since silver have a disinfecting effect and has found uses in traditional medicines for a long time. Silver nanoparticles have high surface specific area, which will lead to excellent antimicrobial activity as compared with bulk metallic silver.

Originally, silver nanoparticles can be synthesized using various chemical and physical methods, but these approaches are not environmentally benign [4]. Each method has advantages and disadvantages with common problems being cost, scalability, wide size distribution [5] and decrease in the stability of the nanoparticles on application can be problematic since aggregation decreases the specific surface area lowering the antimicrobial and catalytic activity [6]. Furthermore, the presence of some toxic metals in the synthesis process may create some adverse effects in biomedical applications [7]. Thus, biosynthesis of nanoparticles emerged as an effective alternative to overcome the disadvantages of the classical methods.

The bio-route attracts a considerable interest because of its ecofriendliness and biocompatibility. A great deal of effort has been put into the biosynthesis of metal nanoparticles, using microorganisms such as bacteria [8,9], fungus [10,11], algae [12], and plants [13]. The use of macro-fungi especially mushroom in the nanoparticle synthesis is a new addition and holds a promising role in large-scale nanoparticle production in lesser time period. In fact, the mushroom fungi produce many proteins and extracellular enzymes involved in the reduction of silver nitrate during the synthesis of silver nanoparticles and are very simple to grow both in lab scale and industrial scale and also the yield is high.

This review intends to present a brief note on the biosynthesis of silver nanoparticles from edible mushroom extract, their characterization using various techniques, antimicrobial and anticancer activity.

\section{BIOSYNTHESIS OF SILVER NANOPARTICLES FROM EDIBLE MUSHROOM EXTRACT}

Mushroom extract was prepared by boiling cut pieces of edible mushroom (Pleurotus sp.) with sterile distilled water for 10 minutes and filtered. The extract was mixed with $1 \mathrm{mM} \mathrm{AgNO}_{3}$ (Fig. 1). The mixture turned brown color which indicates the formation of silver nanoparticles. The nanoparticles are then pelleted and dried.

\section{CHARACTERIZATION OF SILVER NANOPARTICLES}

\section{UV-VIS spectroscopy}

Metal nanoparticles exhibit strong absorption of electromagnetic waves due to surface plasmon resonance in the visible range [14]. Thus, UV-VIS spectroscopy is used to investigate the formation and stability of metal nanoparticles in solution. Dark brown color indicates the production of silver nanoparticles in solution [15].

\section{Fourier transform infrared spectroscopy (FTIR)}

When infrared radiation is passed through a sample, specific wavelengths are absorbed which causes the chemical bonds present in the material to undergo vibrations such as stretching, contracting and bending. Thereby, FTIR can be used to determine the functional groups of the biomolecules in the extract which are responsible for the reduction of the silver ions.

\section{X-ray diffraction (XRD)}

$\mathrm{XRD}$ is a conventional technique used to establish the crystalline nature, domain size, and structure of the nanoparticles [16]. It can be used to look at a single crystal or polycrystalline materials. 


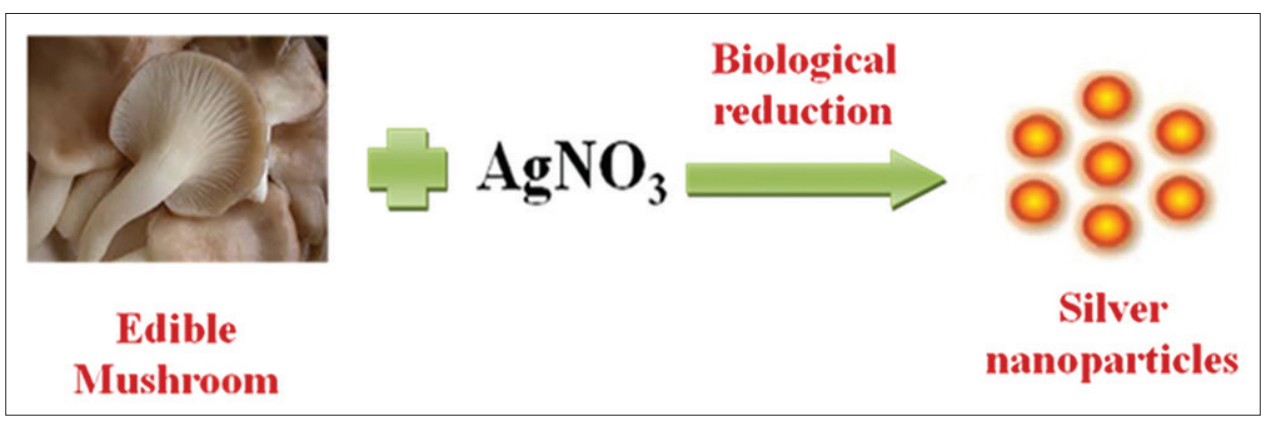

Fig. 1: Schematic representation of silver nanoparticle synthesis

\section{Scanning electron microscopy (SEM)}

SEM is a direct visualization technique used for the morphological examination of nanoparticles. Surface morphology and size of the nanoparticles can be examined, however; this technique provides limited information about the size distribution.

\section{Energy dispersive X-ray spectroscopy (EDX)}

EDX spectroscopy is used for the elemental analysis or chemical characterization of nanoparticle samples. EDX confirms the formation of silver nanoparticles by recording the strong signal of elemental silver.

\section{Transmission electron microscope (TEM)}

TEM is used to study the size and shape of the silver nanoparticles. It is a direct imaging technique, provides higher resolution than SEM. The synthesized silver nanoparticle solution is dropped on carbon-coated TEM grids, dried and viewed for determining the particle size [16]. The sample preparation for TEM is complex and time-consuming because of its requirement to be ultra thin for the electron transmittance under high vacuum.

\section{ANTIMICROBIAL ACTIVITY OF SILVER NANOPARTICLES}

Since several years silver has been known as a strong disinfecting agent and has found many uses in traditional medicinal practices. Several silver-based compounds have been utilized effectively as antimicrobial specialists [17]. Compounds of silver are also used in the medical field to treat burnt wounds and various other types of infections. Nanoparticles of silver have aptly been investigated for their antibacterial property because the silver nanoparticles have high specific area than their volume, which will lead to excellent antimicrobial activity as compared with bulk silver metal [18-21].

Silver nanoparticles showed potential antibacterial activity against Gram-positive bacteria such as Staphylococcus aureus and Bacillus subtilis [22] and Gram-negative organisms such as Klebsiella pneumonia [22] and Salmonella typhus [23]. Praiseworthy endeavors have been made to investigate this property utilizing electron microscopy, which has uncovered size-dependent interaction of silver nanoparticles with microorganisms [19]. However, the inhibitory mechanism of silver nanoparticles is only partially understood. There are different speculations on the activity of silver nanoparticles on microorganisms to bring about the microbicidal impact.

Silver nanoparticles attach with the microbial cell wall membrane by electrostatic attraction $[24,25]$ and subsequently penetrate it, thereby changing the permeability of the cell membrane and causes cell death. Sondi and Salopek-Sondi [26]. stated that the nanoparticles associated with the bacterial cell wall form "pits," thereby affects the permeability and causes cell death.

Electron spin resonance spectroscopy studies proposed that there is the development of free radicals by the silver nanoparticles that might be thought to be another mechanism by which the cells die. At the point when the free radicals formed by the silver nanoparticles are in close contact with the bacteria, they can harm the cell membrane and make it permeable which can at last prompt to cell death $[27,28]$. It was suggested that there can be release of silver ions by the nanoparticles, which acts on the thiol groups of many crucial enzymes and make them inactive, thereby repress several cellular activities and harm the cells [29].

Another reality is that the DNA has sulfur and phosphorus as its important constituents which are soft bases. Silver being a soft acid can act on these soft bases and destroy the DNA which would definitely lead to cell death [19]. The interaction of the silver nanomaterials with the sulfur and phosphorus of the DNA can prompt to issues in the bacterial DNA replication and thus terminate the microscopic organisms (Fig. 2). However, further research is required to thoroughly establish the bactericidal mechanism.

\section{ANTICANCER ACTIVITY OF SILVER NANOPARTICLES}

Nanotechnology plays a tremendous role in overcoming many of the problems that conventional methods face in the treatment, diagnosis, and detection of cancer [31]. The primary feature of these nanoparticles is that their surfaces can be functionalized, exploiting reactive terminal groups, with particular proteins, peptides or monoclonal antibodies that are capable specifically to bind at a site of action or a specific targeted tissue, without interacting with other cells [32]. Therefore, the use of nanotechnology in cancer treatment offers exciting possibility of destroying cancer cells with minimal damage to healthy tissues and organs.

Nanoparticles can be used in the detection and elimination of cancer cells before they form tumors. Nanoparticles can also be designed to carry drugs and release them at the targeted site. These particles can be employed as contrast agents in magnetic resonance imaging for diagnostic purposes and treatment monitoring. In particular, silver nanoparticles secure much enthusiasm among the rising nanoproducts in the field of nanomedicine because of their exceptional properties and clear therapeutic potential in treating a variety of diseases.

Nanoparticles will have a lethal effect on the cell wall of the cancer cells [33]. Water soluble organic moieties in the nanoparticles induce a synergistic antiproliferative effect in various cancer cell lines, thus prove to be useful in various types of cancer control system (Fig. 3).

Silver nanoparticles have been found to induce the apoptotic pathway in vitro through free oxygen radical generation, which showed antitumor, antiproliferative and antiangiogenic effects in-vitro [34]. Compounds having antiangiogenic properties are known for their potential capacity to hinder the action of abnormally expressed signaling proteins, for example, Ras and Akt, subsequently, exhibit a reliable antitumor effect [35].

Cytotoxic activities of silver nanoparticles are documented in the following research works. Asharani et al. [36] reported that silver nanoparticles exhibit antiproliferative effect on human glioblastoma cells. Franco-Molina et al. [37] evaluated the effects of colloidal silver on 


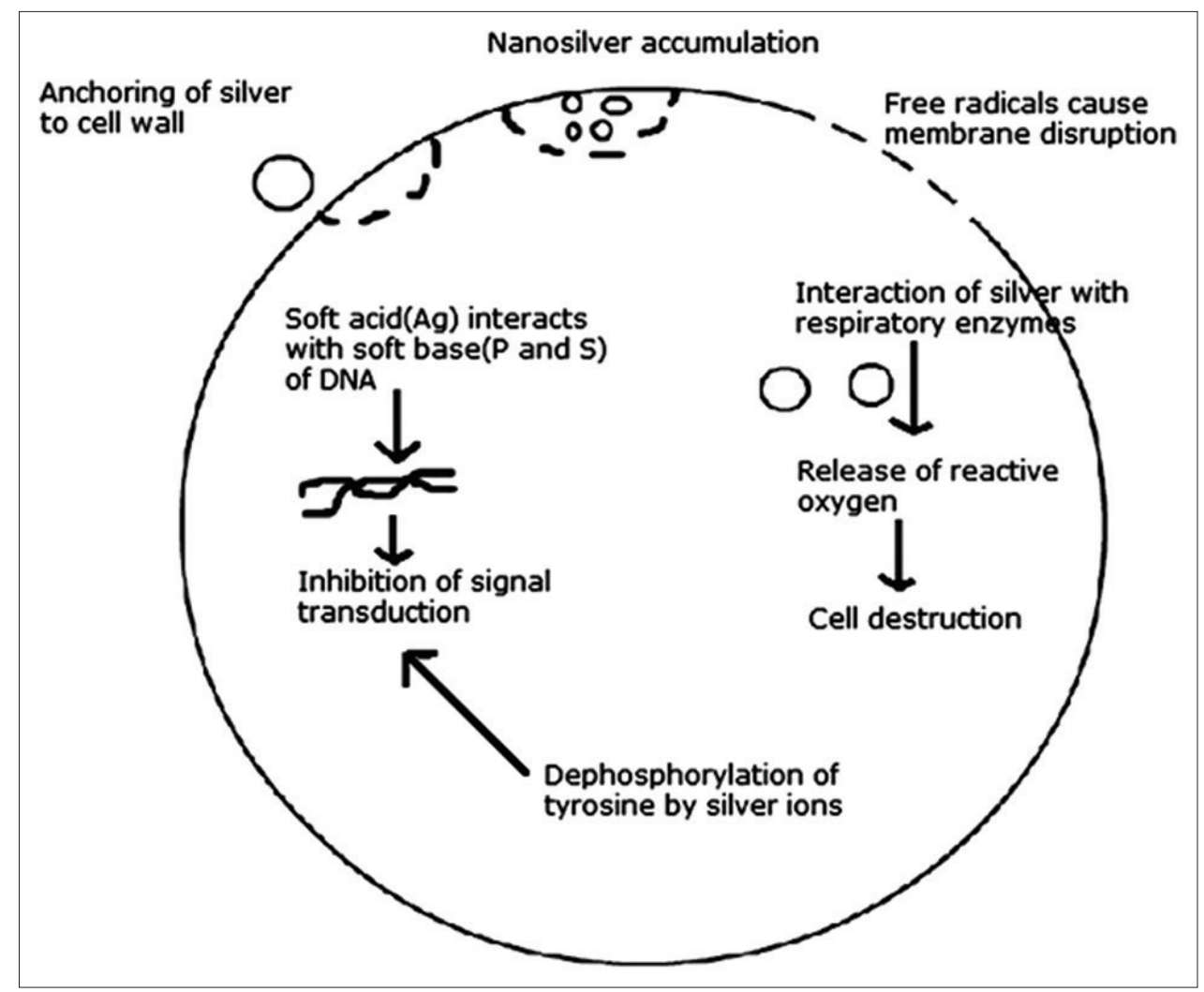

Fig. 2: Various mechanisms of bactericidal action of silver nanoparticles [30]

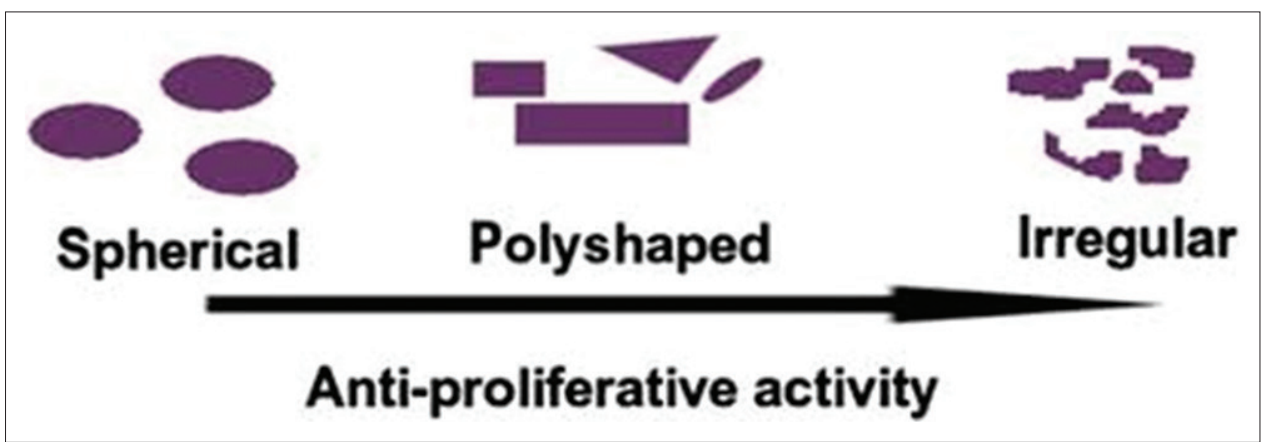

Fig. 3: Antiproliferative activity of nanoparticles [33]

MCF-7 human breast cancer cells. Sanpui et al. [38] demonstrated that nanosilver not only disrupted normal cellular function but also affected membrane integrity, inducing various apoptotic signaling genes of mammalian cells, leading to programmed cell death. Hsin et al. [39] reported that nanosilver induced apoptosis in murine embryonic fibroblast cells (NIH 3T3) by increasing the generation of reactive oxygen species and activating the c-Jun $\mathrm{N}$-terminal kinase pathway, leading to mitochondria-dependent apoptosis. Silver oxide nanoparticles displayed antitumor properties in transplanted Pliss lymphosarcoma tumor models when given through intravenous injection in aqueous form [40]. Silver nanoparticles have shown anticancer activity against some of the human cancer cell lines such as colon carcinoma (HCT-116), breast carcinoma (MCF-7), liver carcinoma (Hep-G2), and intestinal carcinoma (Caco2) as stated by Shawkey et al. [41]. The cytotoxicity of nanosilver is the consequence of dynamic physicochemical interaction of silver particles with the functional groups of intracellular proteins, as well as with the nitrogen bases and phosphate groups of DNA [42].

Silver nanoparticles serve as antitumor agents by decreasing progressive development of tumor cells. This might be because of their inhibitory actions in several signaling cascades liable for the development and pathogenesis of cancer. Taken together, these informations recommend that silver nanoparticles can actuate cytotoxicity on cancer cells and hindering tumor progression without lethality to normal cells.

\section{CONCLUSION}

Biologically prepared silver nanoparticles tend to be biocompatible and cost-effective. Thus, they are handy in wide variety of nanobiotechnology applications. Silver nanoparticle is a good alternative in antibacterial treatment with less side effect and potential action. More research is needed to study the anticancer activity of silver nanoparticles in detail. Under this backdrop, the edible mushroom will be a suitable source for green synthesis of silver nanoparticles having potential anticancer properties. Care has to be taken to utilize this marvel well and in a good, effective and efficient way for human betterment.

\section{ACKNOWLEDGMENTS}

The authors would wish to acknowledge the Head of the Department of Biology, Gandhigram Rural Institute, Deemed University, for providing research facilities and encouragement. 


\section{REFERENCES}

1. Smith AM, Duan H, Rhyner MN, Ruan G, Nie S. A systematic examination of surface coatings on the optical and chemical properties of semiconductor quantum dots. Phys Chem Chem Phys 2006;8:3895-903.

2. Fayaz A, Balaji M, Girilal M, Yadav R, Thangavelu P, Venketesan KR. Biogenic synthesis of silver nanoparticles and their synergistic effect with antibiotics: A study against gram-positive and gram-negative bacteria. Nanomed Nanotechnol Biol Med 2010;6(1):103-9.

3. Jain N, Jain R, Thakur N, Gupta BP, Jain DK, Banveer J, et al. Nanotechnology: A safe and effective drug delivery system. Asian J Pharm Clin Res 2010;3(3):159-65.

4. Dubey SP, Lahtinen M, Sillanpaa M. Tansy fruit mediated greener synthesis of silver and gold nanoparticles. Process Biochem 2010;45(7):1065-71.

5. Evanoff DD Jr, Chumanov G. Synthesis and optical properties of silver nanoparticles and arrays. Chemphyschem 2005;6(7):1221-31.

6. Mafune F, Kohno JY, Takeda Y, Kondow T, Sawabe H. Formation and size control of silver nanoparticles by laser ablation in aqueous solution. J Phys Chem 2000;104(39):9111-7.

7. Bar H, Bhui DH, Sahoo PG, Sarkar P, De PS, Misra A. Green synthesis of silver nanoparticles using latex of Jatrapha curcas. Colloids Surf A Physicochem Eng Asp 2009;339(1-3):134-9.

8. Shahverdi AR, Fakhimi A, Shahverdi HR, Minaian SA. Synthesis and effect of silver nanoparticles on the antibacterial activity of different antibiotics against Staphylococcus aureus and Escherichia coli. Nanomed Nanotechnol Biol Med 2007;3(2):168-71.

9. Kalimuthu K, Suresh Babu R, Venkataraman D, Bilal M, Gurunathan S. Biosynthesis of silver nanocrystals by Bacillus licheniformis. Colloids Surf B Biointerfaces 2008;65:150-3.

10. Basavaraja S, Balaji SD, Lagashetty A, Rajasab AH, Venkataraman A. Extracellular biosynthesis of silver nanoparticles using the fungus Fusarium semitectum. Mater Res Bull 2008;43:1164-70.

11. Balaji DS, Basavaraja S, Deshpande R, Mahesh DB, Prabhakar BK, Venkataraman A. Extracellular biosynthesis of functionalized silver nanoparticles by strains of Cladosporium cladosporioides fungus. Colloids Surf B Biointerfaces 2009;68(1):88-92.

12. Vivek M, Kumar PS, Steffi S, Sudha S. Biogenic silver nanoparticles by Gelidiella acerosa extract and their antifungal effects. Avicenna J Med Biotechnol 2011;3(3):143-8.

13. Vanaja M, Annadurai G. Coleus aromaticus leaf extract mediated synthesis of silver nanoparticles and its bactericidal activity. Appl Nanosci 2013;3(3):217-23

14. Amin M, Anwar F, Janjua MR, Iqbal MA, Rashid U. Green synthesis of silver nanoparticles through reduction with Solanum xanthocarpum L. Berry extract: Characterization, antimicrobial and urease inhibitory activities against Helicobacter pylori. Int J Mol Sci 2012;13(8):9923-41.

15. Shankar SS, Rai A, Ankamwar B, Singh A, Ahmad A, Sastry M. Biological synthesis of triangular gold nanoprisms. Nat Mater 2004;3:482-8

16. Lathamuthiah B, Devi R. In vivo toxicity studies of biosynthesized silver nanoparticles using Brassica oleraceae in zebra fish model. Int J Pharm Pharm Sci 2014;7(2):425-30.

17. Nomiya K, Yoshizawa A, Tsukagoshi K, Kasuga NC, Hirakawa S, Watanabe J. Synthesis and structural characterization of silver(I), aluminium(III) and cobalt(II) complexes with 4-isopropyltropolone (hinokitiol) showing noteworthy biological activities. Action of silver(I)-oxygen bonding complexes on the antimicrobial activities. J Inorg Biochem 2004;98(1):46-60.

18. Panacek A, Kvítek L, Prucek R, Kolar M, Vecerova R, Pizúrova N, et al. Silver colloid nanoparticles: Synthesis, characterization, and their antibacterial activity. J Phys Chem B 2006;110:16248-53.

19. Morones JR, Elechiguerra JL, Camacho A, Holt K, Kouri JB, Ramírez JT, et al. The bactericidal effect of silver nanoparticles. Nanotechnology 2005;16:2346-53.

20. Baker C, Pradhan A, Pakstis L, Pochan DJ, Shah SI. Synthesis and antibacterial properties of silver nanoparticles. J Nanosci Technol 2005;5(2):244-9.
21. Rai M, Yadav A, Gade A. Silver nanoparticles as a new generation of antimicrobials. Biotechnol Adv 2009;27(1):76-83.

22. Mahitha B, Raju BD, Dillip GR, Reddy CM, Mallikarjuna K, Manoj L, et al. Biosynthesis, characterization and antimicrobial studies of AgNPs extract from Bacopa monniera whole plant. Dig J Nanomater Biostruct 2011;6(1):135-42.

23. Tripathi RM, Saxena A, Gupta N, Kapoor H, Singh RP. High antibacterial activity of silver nanoballs against $E$. coli MTCC 1302, $S$. typhimurium MTCC 1254, B. subtilis MTCC 1133 and $P$. aeruginosa MTCC 2295. Dig J Nanomater Biostruct 2010;5(2):323-30.

24. Dibrov P, Dzioba J, Gosink KK, Häse CC. Chemiosmotic mechanism of antimicrobial activity of $\mathrm{Ag}($ ?) in Vibrio cholerae. Antimicrob Agents Chemother 2002;46:2668-70.

25. Lara HH, Ayala-Nuaez NV, Ixtepan-Turrent L, Rodriguez-Padilla C. Bactericidal effect of silver nanoparticles against multidrug-resistant bacteria. World J Microbiol Biotechnol 2010;26(4):615-21.

26. Sondi I, Salopek-Sondi B. Silver nanoparticles as antimicrobial agent: A case study on E. coli as a model for Gram-negative bacteria. J Colloid Interface Sci 2004;275:177-82.

27. Danilczuk M, Lund A, Sadlo J, Yamada H, Michalik J. Conduction electron spin resonance of small silver particles. Spectrochim Acta A Mol Biomol Spectrosc 2006;63(1):189-91.

28. Kim JS, Kuk E, Yu KN, Kim JH, Park SJ, Lee HJ, et al. Antimicrobial effects of silver nanoparticles. Nanomedicine 2007;3(1):95-101.

29. Feng QL, Wu J, Chen GQ, Cui FZ, Kim TN, Kim JO. A mechanistic study of the antibacterial effect of silver ions on Escherichia coli and Staphylococcus aureus. J Biomed Mater Res 2000;52(4):662-8.

30. Prabhu S, Poulose EK. Silver nanoparticles: Mechanism of antimicrobial action, synthesis, medical applications, and toxicity effects. Int Nano Lett 2012;2(1):1-10.

31. Yeole MP, Dhole SN, Kulkarni NS. Peptide nanomedicine in cancer treatment. Asian J Pharm Clin Res 2013;6(2):28-32.

32. Preethi R, Padma PR. Anticancer activity of silver nanobio-conjugates synthesized from Piper betle leaves extract and its active compound eugenol. Int J Pharm Pharm Sci 2016;8(9):201-5.

33. Raghunandan D, Ravishankar B, Sharanbasava G, Mahesh DB, Harsoor V, Yalagatti MS, et al. Anti-cancer studies of noble metal nanoparticles synthesized using different plant extracts. Cancer Nanotechnol 2011;2(1-6):57-65.

34. Gurunathan S, Lee KJ, Kalimuthu K, Sheikpranbabu S, Vaidyanathan R, Eom SH. Antiangiogenic properties of silver nanoparticles. Biomaterials 2009;30(31):6341-50.

35. Martins D, Frungillo L, Anazzetti MC, Melo PS, Durán N. Antitumoral activity of L-ascorbic acid-poly- D, L-(lactide-co-glycolide) nanoparticles containing violacein. Int J Nanomedicine 2010;5:77-85.

36. AshaRani PV, Low Kah Mun G, Hande MP, Valiyaveettil S. Cytotoxicity and genotoxicity of silver nanoparticles in human cells. ACS Nano 2009;3(2):279-90.

37. Franco-Molina MA, Mendoza-Gamboa E, Sierra-Rivera CA, GómezFlores RA, Zapata-Benavides P, Castillo-Tello P, et al. Antitumor activity of colloidal silver on MCF-7 human breast cancer cells. J Exp Clin Cancer Res 2010;29:148.

38. Sanpui P, Chattopadhyay A, Ghosh SS. Induction of apoptosis in cancer cells at low silver nanoparticle concentrations using chitosan nanocarrier. ACS Appl Mater Interfaces 2011;3:218-28.

39. Hsin YH, Chen CF, Huang S, Shih TS, Lai PS, Chueh PJ. The apoptotic effect of nanosilver is mediated by a ROS-and JNK-dependent mechanism involving the mitochondrial pathway in NIH3T3 cells. Toxicol Lett 2008;179(3):130-9.

40. Rutberg FG, Dubina MV, Kolikov VA, Moiseenko FV, Ignat'eva EV, Volkov NM, et al. Effect of silver oxide nanoparticles on tumor growth in vivo. Dokl Biochem Biophys 2008;421:191-3.

41. Shawkey AM, Rabeh MA, Abdulall AK, Abdellatif AO. Green nanotechnology: Anticancer activity of silver nanoparticles using Citrullus colocynthis aqueous extracts. Adv Life Sci Technol 2013;13:60-70.

42. Sriram MI, Kanth SB, Kalishwaralal K, Gurunathan S. Antitumor activity of silver nanoparticles in Dalton's lymphoma ascites tumor model. Int J Nanomedicine 2010;5:753-62. 